\title{
Retos del desempeño docente en el siglo XXI: una visión del caso peruano
}

\author{
Esquerre Ramos, Lucía Angélica; Pérez Azahuanche, Manuel Ángel \\ Retos del desempeño docente en el siglo XXI: una visión del caso peruano \\ Revista Educación, vol. 45, núm. 2, 2021 \\ Universidad de Costa Rica, Costa Rica \\ Disponible en: https://www.redalyc.org/articulo.oa?id=44066178033 \\ DOI: https://doi.org/10.15517/revedu.v45i1.43846
}

\section{(c)}

Esta obra está bajo una Licencia Creative Commons Atribución-NoComercial-SinDerivar 3.0 Internacional. 
Revisiones bibliográficas

\title{
Retos del desempeño docente en el siglo XXI: una visión del caso peruano
}

\author{
The Challenge of Teacher Performance in the XXIst Century: A Glance at Peru \\ Lucía Angélica Esquerre Ramos \\ Universidad César Vallejo, Perú \\ DOI: https://doi.org/10.15517/revedu.v45i1.43846 \\ luciaesquerreramos@gmail.com \\ Redalyc: https://www.redalyc.org/articulo.oa? \\ $\mathrm{id}=44066178033$
}

iD https://orcid.org/0000-0002-0424-6310

Manuel Angel Pérez Azahuanche

Universidad César Vallejo, Perú

manuelangelperez@gmail.com

iD https://orcid.org/0000-0003-4829-6544

Recepción: 04 Octubre 2020

Aprobación: 09 Diciembre 2020

\section{Resumen:}

La tarea docente siempre ha sido motivo de preocupación y discusión entre las personas encargadas de las políticas educativas en los diversos países del orbe, lo que ha generado, en las últimas décadas, propuestas respecto a los criterios e indicadores que permitan evaluar si la práctica docente es o no la adecuada, y si responde a las exigencias del nuevo siglo. El presente artículo analiza, desde una mirada holística, el desempeño docente en el contexto de la sociedad actual; se fundamenta en la revisión de las bases de las normativas internacionales y nacionales, que precisan criterios sobre el valor de la educación y el rol del personal docente; las principales teorías y enfoques pedagógicos; las concepciones sobre el desempeño docente y los diversos indicadores que permiten su evaluación, con la finalidad de arribar a una propuesta de perfil de la persona docente del siglo XXI. Se basa en una revisión sistemática, apoyada en el uso del protocolo Prisma para seleccionar investigaciones publicadas en los últimos diez años en las bases de datos Scopus, Web of Science, Scielo y Redalyc. Para el análisis de los estudios seleccionados se consideraron objetivos, resultados y, principalmente, las propuestas que plantean perfiles y criterios del desempeño docente para el presente siglo. Entre los principales hallazgos se evidencia la necesidad de que el personal docente sea capaz de analizar y adecuar su práctica pedagógica en función de las necesidades del contexto, que emprenda e innove permanentemente con la implementación adecuada de las tecnologías de la información y comunicación, y que se preocupe por desarrollar aprendizajes que beneficien el desarrollo social. Las políticas educativas desarrolladas en diversos países para favorecer la práctica docente, emiten normas para un óptimo desenvolvimiento en las aulas y una participación más allá de ellas, tanto a nivel institucional como social, responden a esta necesidad. Para el caso peruano, a través de los dominios establecidos en el Marco del Buen Desempeño Docente que, para efectos de evaluación solo considera el desempeño en el aula y que es necesario modificar, incorporando entre otros criterios, la competencia digital de manera prioritaria.

Palabras Clave: Práctica pedagógica, Competencias docentes, Evaluación docente, Desempeño docente.

\section{Abstract:}

Teaching has always stirred great concern and discussion among educational policymakers throughout the world. In recent decades, different proposals have arisen about evaluating teaching based on criteria and indicators that qualify its effectiveness and capacity to respond to the demands of the new century. A holistic approach is used herein to assess teaching within the context of today's society, based on a review of national and international regulatory educational policies that establish criteria on the value of education, the role of teachers and the main pedagogical theories and approaches. It also discusses notions about teaching and assessment indicators to establish a profile of a $21^{\text {st }}$ century teacher. A systematic review based on the Prisma protocol was used to select studies dating back to the last ten years from various databases that include Scopus, Web of Science, Scielo and Redalyc. When analyzing the selected studies, aspects that were considered included objectives, results and teacher performance in this century. Findings include a teacher's capacity to be analytical and adapt their teaching practice to different contexts. They should continuously be willing to venture and innovate, use information and communication technology appropriately, be conscientious and use learning to benefit social development. Educational policies in many countries support teachers by issuing regulations that foster optimum teacher participation and development within the classroom and encourage their involvement and respond to this need both institutionally and socially . 
KEYWORDS: Pedagogical Practice, Teacher Skills, Teacher Assessment, Teaching Performance.

\section{INTRODUCCIÓN}

El desempeño docente constituye una variable fundamental dentro del ámbito educativo, especialmente cuando se refiere al desarrollo de aprendizajes en el estudiantado; sin embargo, durante mucho tiempo, este no ha podido ser precisado con total claridad, en buena parte debido a los numerosos cambios en las concepciones pedagógicas que le asignaban determinado rol al docente. Al igual que en muchos países latinoamericanos, en el Perú, el Ministerio de Educación [MINEDU]. ha priorizado, dentro de sus políticas, la evaluación del desempeño docente, tal como lo establece en la Ley 29944. Esta se inició con el profesorado de Educación Inicial y, si bien los resultados no han sido desalentadores, ya que solo un 0,7\% de ellos desaprobaron dicha evaluación (Ministerio de Educación [MINEDU], 2019); estos solo están referidos a desempeños precisados en la rúbrica de observación de aula; lo cual deja de lado otros criterios o desempeños que se deberían considerar.

Ya en el siglo XXI, caracterizado por grandes retos que han obligado a repensar la práctica pedagógica, es necesario clarificar qué involucra el desempeño docente y cuáles son las implicancias que tiene para el logro de las competencias del estudiantado y, por tanto, en la calidad educativa; la cual no solo se mide por la infraestructura y los recursos con que se cuenta, sino, fundamentalmente, se valora por la capacidad docente y el mejoramiento de la enseñanza y el aprendizaje, acorde con las necesidades del contexto; pues, como señala UNESCO (2014), para lograr que los aprendizajes mejoren, debe promoverse que en los proyectos educativos se considere optimizar la gestión y la calidad del personal docente, porque el aprendizaje y la enseñanza de calidad, sin duda, demandan una adecuada formación y el continuo fortalecimiento de las capacidades docentes en diferentes ámbitos, como la planificación, evaluación, estrategias metodológicas, etc.(Cóndor y Remache, 2019).

En consecuencia, el presente artículo de revisión pretende ofrecer un perfil docente del presente siglo, a través de una visión clara y precisa de las competencias que debe desarrollar como parte de su trabajo cotidiano, no solo en el aula, sino en todo aquello que involucre su función, acorde a los requerimientos de la sociedad actual, con el fin de que las instituciones pertinentes las prioricen en los procesos de evaluación.

Si bien son muchas las investigaciones que se han desarrollado respecto al desempeño docente y que se incluyen en la presente investigación por las diferentes perspectivas y criterios que aportan; se ha considerado fundamental partir desde un abordaje de las normativas internacionales y nacionales, que brindan el sustento a las políticas educativas y una revisión de las teorías del aprendizaje que determinan los roles que le corresponde a las personas involucradas y que se convierte en el soporte del desempeño docente del presente siglo.

\section{Sustentos NORMATIVOS ACERCA DEL DESEMPEÑO DOCENTE}

La educación es un derecho inalienable para todas las personas, lo cual está estipulado en el Art. 26 de la Declaración Universal de los Derechos Humanos, documento rector de todas las naciones. En él se señala que la educación pretende desarrollar por completo la personalidad de las personas y fortalecer el respeto por los derechos de cada ser humano y sus libertades fundamentales (Naciones Unidas, 2015). En este sentido, educar implica una formación integral que permita a la persona vivir con dignidad en una sociedad justa e igualitaria. Por ello, todos los países han desarrollado grandes esfuerzos para asegurar el derecho de todos a la educación, pero una educación de calidad que le ayude al estudiantado a desenvolverse adecuadamente en el contexto o realidad que le toque afrontar. 
Por otra parte, la educación, como señalan López y López (2019), es el cimiento para la vida de las personas, ya que de ella depende la formación de la sociedad que el mundo necesita, con una ciudadanía capaz de incorporarse a la vida social, productiva y familiar; en pocas palabras, personas que comprenden el significado de vivir en sociedad. Entonces, si la educación brinda las bases para el desarrollo de la sociedad, se requiere analizarla desde todos los ángulos y componentes que la conforman. Y, justamente, hablar de educación obliga a referirse a uno de sus elementos fundamentales como es el personal docente, cuya concepción sobre su función ha ido transformándose con el devenir del tiempo y de acuerdo con las diferentes teorías educativas que han tratado de explicar su tarea; no obstante, siempre se ha tenido en claro su rol fundamental en todo proceso educativo, ya sea como mediador, facilitador, formador o guía.

Bajo esta concepción de educación como derecho prioritario, en 2002, las personas responsables de los Ministerios de Educación del continente americano elaboraron el Proyecto Regional de Educación para América Latina y el Caribe (PRELAC), en el cual concluyen que uno de los aspectos pendientes de la situación educativa en Latinoamérica está referido al cuerpo docente, que, a pesar de ser el factor más importante en la estructura educativa, aún carece de políticas educativas que articulen su formación inicial en servicio de su desempeño. Es fundamental cambiar el papel desempeñado por cada agente educativo en la denominada educación tradicional, caracterizada por la transmisión vertical de contenidos, ínfima autonomía para el diseño y evaluación curricular, resistencia al cambio y la innovación pedagógica, además de un trabajo individualista y poco cooperativo; por docentes con nuevas competencias que les posibiliten enfrentarse a los desafíos de la educación del presente siglo (UNESCO, 2002).

El cuerpo docente forma personas y, en definitiva, esta no es una tarea sencilla de desarrollar, sino que requiere de una verdadera vocación y, permanentemente, de la necesidad de transformar y adaptar su práctica a la realidad y al contexto. No obstante, la realidad del desempeño docente en Perú, reflejada en muchos estudios e investigaciones, demuestra que persisten las prácticas tradicionales que promueven la apatía y el aburrimiento en el estudiantado y todo ello, sin duda, afecta notablemente los resultados de aprendizaje que se encuentran lejos de lo esperado. Cárdenas (2015), en su tesis Rúbrica y desempeño docente en la provincia de Huancayo, aplica un instrumento para evaluar el nivel de desempeño docente desde siete dimensiones, como se observa en la Tabla 1: 
TABLA 1

Nivel de desempeño docente del profesorado por nivel

\begin{tabular}{|c|c|c|c|c|c|}
\hline \multirow{2}{*}{ Dimensión } & \multirow{2}{*}{ Nivel } & \multicolumn{4}{|c|}{ Nivel de desempeño } \\
\hline & & Deficie & e Regular & Satisfactorio & Muy satisfactorio \\
\hline \multirow{3}{*}{ Planificación } & Inicial & & $11,27 \%$ & $49,30 \%$ & $39,44 \%$ \\
\hline & Primaria & $1,80 \%$ & $13,77 \%$ & $57,19 \%$ & $27,25 \%$ \\
\hline & Secundaria & $0,87 \%$ & $12,72 \%$ & $50,87 \%$ & $35,55 \%$ \\
\hline \multirow{3}{*}{ Metodología } & Inicial & & $7,04 \%$ & $53,52 \%$ & $39,44 \%$ \\
\hline & Primaria & $1,20 \%$ & $16,77 \%$ & $56,89 \%$ & $25,15 \%$ \\
\hline & Secundaria & $0,29 \%$ & $10,40 \%$ & $56,07 \%$ & $33,24 \%$ \\
\hline \multirow{3}{*}{ Evaluación } & Inicial & $1,41 \%$ & $12,68 \%$ & $45,07 \%$ & $40,85 \%$ \\
\hline & Primaria & $0,90 \%$ & $19,46 \%$ & $48,50 \%$ & $31,14 \%$ \\
\hline & Secundaria & $0,87 \%$ & $12,14 \%$ & $51,16 \%$ & $35,84 \%$ \\
\hline \multirow{3}{*}{ Clima para el aprendizaje } & Inicial & & $4,23 \%$ & $40,85 \%$ & $54,93 \%$ \\
\hline & Primaria & $1,80 \%$ & $7,49 \%$ & $47,01 \%$ & $43,71 \%$ \\
\hline & Secundaria & $0,58 \%$ & $4,62 \%$ & $45,09 \%$ & $49,71 \%$ \\
\hline \multirow{3}{*}{ Tiempo en el aula } & Inicial & & $7,04 \%$ & $39,44 \%$ & $53,52 \%$ \\
\hline & Primaria & $2,40 \%$ & $12,28 \%$ & $50,60 \%$ & $34,73 \%$ \\
\hline & Secundaria & $0,87 \%$ & $10,40 \%$ & $49,42 \%$ & $39,31 \%$ \\
\hline \multirow{3}{*}{ Recursos y materiales } & Inicial & & $5,63 \%$ & $45,07 \%$ & $49,30 \%$ \\
\hline & Primaria & $2,10 \%$ & $14,07 \%$ & $48,50 \%$ & $35,33 \%$ \\
\hline & Secundaria & $0,58 \%$ & $7,51 \%$ & $49,13 \%$ & $42,77 \%$ \\
\hline \multirow{3}{*}{ Desempeño docente } & Inicial & & $1,41 \%$ & $45,07 \%$ & $53,52 \%$ \\
\hline & Primaria & $0,90 \%$ & $9,58 \%$ & $53,29 \%$ & $36,23 \%$ \\
\hline & Secundaria & $0,58 \%$ & $3,76 \%$ & $54,91 \%$ & $40,75 \%$ \\
\hline
\end{tabular}

Fuente: Cárdenas (2015)

Luego de la aplicación de la rúbrica, establece como conclusión que, si bien los porcentajes de desempeño satisfactorio y muy satisfactorio son altos, también hay resultados preocupantes, especialmente en el nivel primaria en el que un $9,58 \%$ se ubica en nivel regular y un $0,9 \%$ en nivel deficiente, a diferencia de los de educación inicial y secundaria.

Estos resultados persisten en una problemática recurrente durante muchos años. A pesar de que, en el año 2007, el Proyecto Educativo Nacional al 2021 precisa como uno de sus objetivos estratégicos: contar con profesorado competente para que pueda ejercer profesionalmente la docencia. Sin duda, este objetivo se propone revalorar la labor docente para garantizar su desarrollo profesional a partir de una carrera pública fundamentada en el desempeño eficaz y responsable, así como en una formación permanente y holística (Consejo Nacional de Educación, 2007).

Más adelante, en 2012, la Ley de Reforma Magisterial en sus artículos 13 y 24, referidos a las evaluaciones en la carrera pública magisterial, señalan que se deben realizar, entre otras, la evaluación del desempeño docente con la finalidad de verificar, bajo criterios señalados por el Ministerio de Educación, el nivel de progreso de las competencias profesionales, tanto en el aula y la institución educativa como en la comunidad (Ley 29944, 2012). Todo ello, como se precisa en el Reglamento de la misma Ley, con fines formativos que permitan a las instancias correspondientes determinar las acciones de formación que resulten para asegurar la permanente mejora de la práctica docente.

Esta propuesta de evaluación la asume el Ministerio de Educación, quien publica el documento denominado Marco de Buen Desempeño Docente, en el que propone un conjunto de cambios en la práctica pedagógica como fundamento para la aplicación de las tan ansiadas acciones y políticas de preparación, evaluación y desarrollo del personal docente a nivel nacional. Este documento precisa que la búsqueda de una nueva docencia debe prepararse en cuatro aspectos, a los cuales nombra como dominios: las acciones de preparación para el logro del aprendizaje del estudiantado, el desarrollo de la enseñanza para el aprendizaje, la participación en la gestión de la escuela vinculada a la comunidad y el desarrollo de su profesionalidad e identidad como docente (Ministerio de Educación [MINEDU], 2012). Cada dominio precisa un conjunto 
de competencias que deberá desarrollar cada docente en aras de un mejor desempeño de su labor. De las nueve competencias, tres de ellas están referidas al proceso de enseñanza de los aprendizajes; lo cual se convierte en un indicador de la prioridad que se le otorga a este dominio sobre los otros tres, como se presenta en la Tabla 2 y que se evidencia en el instrumento que el MINEDU ha diseñado para evaluar el desempeño de los docentes de educación básica.

TABLA 2

Dominios y competencias

\begin{tabular}{|c|c|}
\hline $\begin{array}{l}\text { Dominio } 1 \text { Preparación } \\
\text { para el aprendizaje del } \\
\text { estudiantado }\end{array}$ & $\begin{array}{l}\text { Competencia } 1 \text { Conoce y comprende las características de casa estudiante y su contexto; los contenidos disciplinares que enseña, } \\
\text { los enfoques y procesos pedagógicos, con el propósito de promover capacidades de alto nivel y su formación integral. } \\
\text { Competencia } 2 \text { Planifica la enseñanza de forma colegiada, garantiza la coherencia entre los aprendizajes que quiere lograr en sus } \\
\text { estudiantes, el proceso pedagógico, el uso de los recursos disponibles y la evaluación, esto en una programación curricular en } \\
\text { permanente revisión. }\end{array}$ \\
\hline $\begin{array}{l}\text { Dominio } 2 \text { Enseñanza } \\
\text { para el aprendizaje del } \\
\text { estudiantado }\end{array}$ & $\begin{array}{l}\text { Competencia } 3 \text { Crea un clima propicio para el aprendizaje, la convivencia democrática y la vivencia de la diversidad en todas sus } \\
\text { expresiones, con miras a formar una ciudadania crítica e intercultural. } \\
\text { Competencia } 4 \text { Conduce el proceso de enseñanza con dominio de los contenidos disciplinares y el uso de estrategias y recursos } \\
\text { pertinentes, para que cada estudiante aprenda de manera reflexiva y crítica lo que le concierne a la solución de problemas } \\
\text { relacionados con sus experiencias, intereses y contextos culturales. } \\
\text { Competencia } 5 \text { Evalúa permanentemente el aprendizaje de acuerdo con los objetivos institucionales previstos, para tomar } \\
\text { decisiones y retroalimentar a sus estudiantes y a la comunidad educativa, mientras toma en cuenta las diferencias individuales y } \\
\text { los contextos culturales. }\end{array}$ \\
\hline $\begin{array}{l}\text { Dominio } 3 \\
\text { Participación en la } \\
\text { gestión de la escuela } \\
\text { articulada a la } \\
\text { comunidad }\end{array}$ & $\begin{array}{l}\text { Competencia } 6 \text { Participa activamente, con actitud democrática, crítica y colaborativa, en la gestión de la escuela, contribuye a la } \\
\text { construcción y mejora continua del Proyecto Educativo Institucional, para que este pueda generar aprendizajes de calidad. } \\
\text { Competencia } 7 \text { Establece relaciones de respeto, colaboración y corresponsabilidad con las familias, la comunidad y otras } \\
\text { instituciones del Estado y la sociedad civil; aprovecha sus saberes y recursos en los procesos educativos y da cuenta de los } \\
\text { resultados. }\end{array}$ \\
\hline $\begin{array}{l}\text { Dominio } 4 \text { Desarrollo } \\
\text { de la profesionalidad e } \\
\text { identidad docente }\end{array}$ & $\begin{array}{l}\text { Competencia } 8 \text { Reflexiona sobre su práctica y experiencia institucional y desarrolla procesos de aprendizaje continuo de modo } \\
\text { individual y colectivo, para construir y afirmar su identidad y responsabilidad profesional. } \\
\text { Competencia } 9 \text { Ejerce su profesión desde una ética de respeto de los derechos fundamentales de las personas, demuestra } \\
\text { honestidad, justicia, responsabilidad y compromiso con su función social. }\end{array}$ \\
\hline
\end{tabular}

Fuente: (Ministerio de Educación [MINEDU], 2012).

A nivel internacional, las preocupaciones al respecto continúan; en 2018, las Naciones Unidas proponen objetivos de desarrollo sostenible y, en el objetivo 4, hacen referencia a la necesidad de fortalecer una educación de calidad, que garantice el carácter inclusivo y equitativo, así como el impulso de oportunidades de aprendizaje permanente para todas las personas. Este objetivo tiene como una de sus metas que hacia el año 2030 se deberá aumentar, de manera considerable, la oferta de docentes competentes (Naciones Unidas - CEPAL, 2018).

Por otra parte, el Proyecto Educativo Nacional a 2036 señala que, si bien el Estado debe responder por el derecho a la educación, no es el único responsable; lo es también el propio estudiantado, personal docente, padres y madres de familia, sociedad civil, etc. Además, precisa que toda política educativa se debe sustentar en el principio de equidad, a fin de que se provea una educación de calidad (Consejo Nacional de Educación, 2020). En este sentido, la labor del profesorado se torna fundamental, dado que es un agente que garantizará el derecho de educación de calidad para toda la población estudiantil peruana.

Estas normativas y precisiones, tanto a nivel internacional como nacional, permiten entender que la educación es un proceso cambiante, que responde a las necesidades propias del contexto y la época que se vive. Entonces, cuando se hace referencia al personal docente y a su desempeño, se debe contemplar que se necesitan criterios claros, bajo los cuales se debe evaluar y que estos criterios estén fundamentados en las diversas teorías que sustentan la acción educativa actual: la educación basada en competencias. 


\section{TEORÍAS, MODELOS Y ENFOQUES, EJES DEL DESEMPEÑO DOCENTE}

Para poder precisar los criterios que, en el presente siglo, deben considerarse en el desempeño docente, es necesario entender los modelos y enfoques educativos, pues estos sustentan la particular relación entre docente, conocimiento y estudiante, al establecer los rasgos fundamentales y niveles de jerarquización (De Zubiría, 1999); es decir, determinan las estrategias y recursos que el cuerpo docente empleará en las aulas.

La propuesta de educación peruana, como se plantea en el Currículo Nacional, usada como sustento para la práctica docente en todas las instituciones y programas educativos públicos, impulsa la innovación y empleo de nuevas estrategias metodológicas y prácticas educativas que garanticen la calidad en los resultados de aprendizaje (Ministerio de Educación [MINEDU], 2016), que tienen su origen en los siguientes enfoques:

El enfoque cognitivista señala que es el estudiantado quien desarrolla por sí mismo procesos cognitivos elementales y superiores que le permiten la asimilación de los conocimientos. Asimismo, precisa que el conocimiento es un acto interno del desarrollo humano, el cual le permite comprender su contexto, adaptarse y actuar en él. En la medida que la persona se desarrolla, interactúa con el saber y aprende más a través de la práctica. En conclusión, mientras mayor experiencia se adquiere, mayor aprendizaje se logra.

El constructivismo señala la necesidad de dotar al estudiantado de herramientas necesarias que le permitan solucionar una determinada situación problemática a través de la creación de sus propias estrategias. En resumen, este modelo plantea que para llegar al conocimiento se requiere que la persona analice e interprete la nueva información, que le permita gradualmente construir interpretaciones cada vez más complejas y potentes para su adaptación al medio, como producto de su interacción con este. Jean Piaget, quien propone esta teoría, señala que el aprendizaje no es producto del azar, sino el resultado de procesos mentales que permiten la elaboración de conclusiones con respecto a lo que sus sentidos perciben y que la inteligencia se desarrolla por cuatro factores principales: la influencia del medio social, la maduración, la experiencia y el equilibrio (Piaget,1969). Al ser el aprendizaje producto de los procesos intelectuales que se desarrollan en la persona, el cuerpo docente adquiere una función relevante, en el sentido que debe promover el desarrollo de esos procesos mentales a través de diferentes estrategias y recursos.

En la teoría de Piaget, la pedagogía adquiere gran importancia pues el estudiantado tiene la capacidad de progresar por sí mismo, pero siempre con el apoyo de especialistas en educación. Lo anterior ha permitido reconocer la labor que este grupo profesional tiene como favorecedor del desarrollo de sus estudiantes, a través de la propuesta de actividades adecuadas a sus características y nivel de desarrollo, así como el uso de entornos de aprendizaje propicios (Bravo, Loor y Saldarriaga, 2016). Desde esta perspectiva, si se quiere evaluar su desempeño, entonces es importante tener claro que ya no se habla de la persona docente como transmisora de conocimientos y en relación vertical con el estudiantado; sino como quien cumple el rol de orientar y facilitar el aprendizaje; para lo cual requiere conocer sus características de desarrollo intelectual en cada etapa, a fin de crear condiciones apropiadas para el aprendizaje (Ortiz, 2017).

Ausubel, hacia 1963, plantea una teoría que aporta valiosamente al cognitivismo. Él plantea la necesidad de diferenciar el aprendizaje repetitivo o memorístico de un aprendizaje significativo; en este sentido, la persona estudiante debe valorar la importancia que tienen los conocimientos previos, ya que el aprendizaje es comprensión y, para ello, como requisito imprescindible está el considerar lo que el estudiantado ya sabe o conoce sobre aquello que se pretende enseñar. También, plantea como acción pedagógica lograr que sus estudiantes establezcan relaciones significativas entre los conocimientos que ya tiene y los nuevos, a partir de puentes cognitivos, como son los organizadores previos. Por último, defiende una propuesta didáctica, que supere las deficiencias de la práctica educativa tradicional, al tomar en cuenta el punto en el que se inicia el aprendizaje del estudiantado y la estructura y jerarquía de los conceptos (Ausubel, 1978). Entonces, en esta teoría es muy importante que, a través de la actividad docente, se produzcan cambios en las estructuras conceptuales por medio de los procesos de diferenciación progresiva y reconciliación integradora. 
También, desde la perspectiva ausubeliana, a la persona docente debe interesarle fomentar el aprendizaje significativo de sus estudiantes por descubrimiento y recepción, para lo cual debe suscitar en sus clases la práctica de experiencias de aprendizaje que tengan un alto grado de significatividad lógica (estructuración y secuencia coherente de ideas, claridad de expresión, etc.). Además, es necesario que conozca y emplee, de manera efectiva, las denominadas estrategias instruccionales cognitivas en cada una de las situaciones de aprendizaje; pero tampoco debe perder de vista la preocupación por desarrollar, promover y enseñar habilidades cognitivas y metacognitivas en el estudiantado (Ortiz, 2017). Desde esta concepción, el desempeño del cuerpo docente debe partir de una práctica en la que el estudiantado es un sujeto activo que desarrolla aprendizajes significativos, que es capaz de aprender a aprender y de pensar. Así pues, la tarea docente se concentra principalmente en elaborar y establecer experiencias de aprendizaje orientadas hacia esos fines y no en convertirse en el mismo en el centro de la enseñanza.

Otro aporte importante para el enfoque cognitivista es el del aprendizaje por descubrimiento de Brunner. En este, la labor pedagógica consiste en proporcionar al estudiante material contextualizado, para que no solo aprenda, sino que lo haga de tal forma que le sirva como información para resolver futuras situaciones problemáticas. Para Brunner el aprendizaje es un proceso activo y que se desarrolla en un contexto social, el cual le permite al estudiantado la construcción de nuevos conceptos o ideas, basadas en sus conocimientos previos; la persona docente debe promover en el alumnado el interés por descubrir y construir sus propios conocimientos a través de un diálogo activo, en contraste con la enseñanza tradicional. Por ello, Eleizalde, Parra, Palomino, Reyna y Trujillo (2010) hacen referencia a la necesidad de que el profesorado, en las formas de enseñanza por descubrimiento, le ofrezca al estudiantado la posibilidad de manipular objetos para que puedan transformarlos por acción directa; además de un conjunto de actividades que le permita buscar, explorar y analizar, ya que estos procedimientos, más allá de incrementar el conocimiento acerca de un tema, incentivan su curiosidad y favorecen el desarrollo de estrategias para aprender a aprender que, en la realidad actual, es una acción fundamental del actuar pedagógico.

El fin o propósito de la educación ya no es la adquisición de conocimientos, sino que estos se convierten en el medio del cual se vale el estudiantado para percatarse de la realidad en la que vive. En ese sentido, asume gran importancia el enfoque crítico, que es uno de los que sustenta la propuesta del Ministerio de Educación de Perú. Esta teoría postula que, a partir de la relación que se establece entre la teoría, la práctica y la realidad en condiciones específicas, el conocimiento se constituye como un motor para el cambio social. De esta manera, su finalidad es entender la sociedad para mejorarla y con ello beneficiar la calidad de vida del ser humano. En este enfoque lo más importante es la capacidad que se tenga de interpretar la situación, sus causas históricas y, a partir de ellas, la lectura constante de la teoría y de la realidad y su relación con la situación problema (González, 2014). Los supuestos de la pedagogía crítica, promovida por Paulo Freire y que dan sustento al enfoque crítico, propugnan la enseñanza aprendizaje como un proceso científico; si se ciñe al criterio epistemológico, se debe reconocer que los sujetos del conocimiento científico son tanto docentes como estudiantes, y que lo que se pretende que estudien sería el objeto de conocimiento. El método de aproximación de los sujetos al objeto planteado por la persona docente, serían los procedimientos didácticos que emplea, en primera instancia, el profesorado, pero más adelante, la población estudiantil. Así, la tarea pedagógica del personal docente es saber cómo presentar la incógnita de investigación al alumnado, para que después de comprender el objeto de estudio se proponga investigar sobre él (Ordóñez, 2002). Dicho de otra manera, la práctica docente y la acción de investigar confluyen en el proceso de aprendizaje.

El enfoque histórico cultural promovido por Vygotsky también aporta al enfoque crítico, en la medida que precisa que el aprendizaje no es tan solo un procedimiento de construcción individual, sino que es una actividad social, pues ubica al estudiantado (sujeto activo) en el centro de la atención, pero no como un ente aislado, sino en su interacción con los demás, con sus opiniones, con el objeto y elementos que le permitirán, a su vez, desarrollar transformaciones en sí mismo. 
Finalmente, es necesario referirse al enfoque por competencias, modelo educativo que se sustenta en la enseñanza contextualizada de conocimientos, a los cuales convierte en útiles para el estudiantado, en la medida que le sirven para enfrentarse a situaciones del mundo real. Esto significa que, para este enfoque, lo más importante es saber cómo y cuándo utilizar los contenidos aprendidos para resolver situaciones o problemas reales, ya que cuando se combina el qué y el cómo, se promueve el desarrollo de capacidades cognoscitivas de nivel superior como el análisis, reflexión, creatividad, pensamiento crítico, entre muchas otras; además de desarrollar valores, habilidades interpersonales, actitudes, liderazgo, compromiso, y otras que están referidas al aspecto emocional o afectivo de la persona. Entonces, es evidente que, ante a la enseñanza tradicional centrada en la memorización de contenidos poco relevantes, la propuesta de una educación orientada al desarrollo de competencias prioriza la experimentación y la práctica para la adquisición de conocimientos, con la condición de que estos respondan a las necesidades reales de aprendizaje, y las características, estilos y potencialidades individuales del estudiantado, como la mejor forma de asegurar un verdadero desarrollo de sus habilidades y destrezas.

$\mathrm{Al}$ reconocer que desarrollar competencias en el estudiantado lo acerca a un aprendizaje total, es cuando el rol de la persona docente cambia y se concentra en facilitar el desarrollo de estas a través de un acompañamiento, en el que se promueva que sus aprendizajes adquieran significatividad por la utilidad que tendrán, no solo en su vida presente (cuando se desarrollan) sino en su vida futura, pues le servirán para solucionar problemas de su entorno.

Roegiers (2016) coincide con muchas aproximaciones respecto al rol que cumplen las competencias en los currículos y señala tres propuestas. En primer lugar, es necesario un análisis crítico y reflexivo acerca de lo que se aprende, cómo se aprende y para qué es útil frente a los desafíos actuales. En segundo lugar, se debe considerar que el actor principal del aprendizaje es el estudiantado, por lo cual debe participar cada vez más en sus aprendizajes, de la manera más frecuente como le sea posible y a través de diversas formas: trabajo colaborativo, uso de recursos virtuales, desarrollo de proyectos, etc. Finalmente, se refiere al saber actuar en determinadas situaciones como las que originan y consolidan del aprendizaje, y las situaciones de evaluación que son las situaciones complejas que debe resolver el alumnado y que sirven para evaluarlo.

El inicio del enfoque por competencias en Perú se remonta hacia 1995, año en que, a través del currículo nacional, se plantea un programa de articulación entre la educación inicial y primaria. Los componentes de la competencia aparecían fragmentados; pues, contenidos, capacidades y actitudes se abordaban de forma aislada. Por otro lado, se proponía el desarrollo de competencias por ciclos, mas, en algunos casos, la secuenciación entre un ciclo y otro no conservaba la progresión adecuada. Transcurrieron muchos años y se fueron realizando proyectos y cambios con el fin de mejorar la propuesta: permitieron elaborar el actual currículo nacional que redefine el verdadero significado de la competencia como un saber actuar en una situación determinada, a través de la combinación de variados y diversos aprendizajes que demuestren un desempeño complejo, integral y sistémico. Asimismo, el Currículo Nacional de la Educación Básica propone que el desarrollo de las competencias es una construcción permanente, intencionada y consciente, cuyo desarrollo le corresponde al cuerpo docente y a la institución, y que no concluye en un determinado momento, sino que se da a lo largo de toda la escolaridad, en diferentes niveles.

Estos enfoques permiten entender las necesidades de cambio en educación, que no solo debe darse a nivel de contenidos y capacidades, sino también en las formas en que el personal docente desarrolla su práctica pedagógica, ya que esta motiva y promueve capacidades, valores y actitudes que permitan el desarrollo integral del estudiantado.

\section{Perspectivas del desempeño Docente}

La educación es un derecho primordial y la tarea docente es un pilar para el logro de aprendizajes en el alumnado. Por esta razón, en todo el mundo se han desarrollado políticas educativas orientadas a favorecer el 
mejoramiento de la práctica pedagógica, a través de acciones de monitoreo, acompañamiento, capacitación y evaluación del desempeño.

Granda (2002) realiza, en Ecuador, un estudio en el cual se evalúa el desempeño docente desde la mirada de tres partes involucradas: estudiantes, personas directivas y docentes. Los resultados son favorables, como se aprecia en la Tabla 3.

TABLA 3

Resultados de evaluación del desempeño docente

\begin{tabular}{llll}
\hline $\mathrm{N}^{\circ}$ & $\begin{array}{l}\text { Actores que evaluaron } \\
\text { el desempeño docente }\end{array}$ & $\begin{array}{l}\text { Promedios de evaluación } \\
\text { de los tres semestres } \\
\text { sobre 5 }\end{array}$ & Porcentajes \\
\hline 1 & Estudiantes & 4,17 & $83 \%$ \\
2 & Directores y directoras & 4,51 & $90 \%$ \\
3 & $\begin{array}{l}\text { Docentes } \\
\text { (autoevaluación) }\end{array}$ & 4,53 & $91 \%$ \\
\hline
\end{tabular}

Fuente: Adaptado de Granda (2002).

No obstante, plantea la interrogante de si los resultados obtenidos reflejan objetivamente la realidad. En ese sentido, se considera que la validez de estos depende de variados factores, entre ellos la precisión de los criterios para evaluar. En consecuencia, si los indicadores que se usan para evaluar son ambiguos y no expresan con claridad las dimensiones a evaluarse, los resultados pueden carecer de validez. Así pues, no se puede limitar el desempeño docente tan solo a las competencias pedagógicas, sino que se deben considerar diversos factores adicionales, como el estilo de docencia, la pertinencia y consistencia del currículo, las necesidades formativas del estudiantado, etc.; los cuales, muchas veces, son más definitivos que las competencias.

Para Robalino (2005), reducir el desempeño docente a únicamente una tarea pedagógico-educativa, ya sea en el aula o fuera de ella, aun con criterios innovadores, ubica a la persona docente en una posición pasiva respecto a dimensiones importantes, como la gestión y la política educativa. Por ello, plantea que la práctica pedagógica no solo se refiere al desarrollo de las habilidades profesionales, la disposición y el compromiso social entre los elementos que favorecen la formación del alumnado y relaciones significativas; sino que incluye, también, la contribución en la gestión de la escuela, el favorecimiento del desarrollo de una cultura escolar democrática y la participación en la organización, implementación y evaluación de políticas educativas de todo nivel, para que permitan al estudiantado alcanzar competencias y habilidades para la vida. Más adelante, ratifica su propuesta de que en el trabajo docente se deben analizar tres dimensiones: aprendizaje del alumnado, referida a la misión fundamental de facilitar y promover el aprendizaje; la gestión educativa, ejercida desde una perspectiva de participación, liderazgo compartido e identificación con la visión y misión de la escuela; la dimensión relacionada a las políticas educativas, en las que se requiere su participación responsable y activa (Robalino, 2007).

Por su parte, Montenegro (2007), como resultado del análisis del modelo colombiano de evaluación del desempeño docente planteado en 2000 y 2003 que consideraba 14 criterios de desempeño, señala que este alude al cumplimiento de sus funciones, definidas por variables ligadas al mismo personal docente, al estudiantado y al contexto, y que se precisan en cuatro campos: personal, aula, institucional y entorno, tal como se observa en la Tabla 4. 
TABLA 4

Estructura de los campos en los que se ejerce el desempeño docente

\begin{tabular}{lllll}
\hline Campos & Espacios & Actores & Relación & Objetivo \\
\hline $\begin{array}{l}\text { Personal } \\
\begin{array}{l}\text { Aula y otros } \\
\text { ambientes de } \\
\text { aprendizaje }\end{array}\end{array}$ Privado & $\begin{array}{l}\text { Aulas, laboratorios, } \\
\text { bibliotecas, espacios } \\
\text { deportivos }\end{array}$ & Estudiantado & Pedagógica & $\begin{array}{l}\text { Efectividad en los } \\
\text { aprendizajes del } \\
\text { estudiantado }\end{array}$ \\
\hline Institucional & Institución educativa & $\begin{array}{l}\text { Personal docente, } \\
\text { directivo, trabajador }\end{array}$ & Institucional & $\begin{array}{l}\text { Desarrollo coherente } \\
\text { del PEI }\end{array}$ \\
\hline Entorno & $\begin{array}{l}\text { Barrio, vereda, } \\
\text { municipio, país, } \\
\text { mundo }\end{array}$ & Sociedad en general Social, cultural & $\begin{array}{l}\text { Aportes al } \\
\text { desarrollo social y } \\
\text { cultural }\end{array}$ \\
\hline
\end{tabular}

Fuente: Montenegro (2007).

La consideración de los cuatro campos en este modelo de evaluación colombiano refleja que el desempeño no solo debe centrarse en el ámbito netamente pedagógico, sino que debe considerarse su relación consigo mismo, con la institución y con la sociedad.

La perspectiva de Girón (2014), respecto a las competencias del desempeño docente, es que están referidas a cuatro aspectos concretos: la capacidad para actuar responsable y solidariamente en su entorno; la capacidad para, dentro de un ambiente propicio, colaborar en el desarrollo de un proyecto institucional a través de un trabajo en equipo; la capacidad para identificar necesidades y características del alumnado y orientar sus aprendizajes a partir de la aplicación de estrategias adecuadas a su realidad y la capacidad para construir el currículo con base en políticas educativas, pero de acuerdo con el contexto de la población estudiantil. Por otra parte, concluye que es fundamental el acompañamiento pedagógico que el supervisor pueda realizar, ya que este incide en el desempeño docente.

Padilla (2016) destaca la importancia de que el profesorado desarrolle actividades ligadas a la investigaciónacción; es decir, que despliegue espacios de indagación que le permitan evaluar y reflexionar sobre su propio trabajo, mientras busca nuevas formas de mejorarlas y, así, promover los aprendizajes en sus estudiantes y, sobre todo, fomentar el pensamiento creativo, crítico y complejo. La persona docente, en su práctica, va a desarrollar procesos que conforman su labor fundamental en la sociedad al atender asuntos del ámbito didáctico, pedagógico, curricular y formativo; los cuales impactan de manera directa o indirecta en los contextos en que interactúa, como el aula, la institución, la comunidad, etc. No obstante, aun cuando estos son procesos que responden a las tareas que antiguamente se le asignaron, también se hace referencia a aquellas que la sociedad ha incorporado a su acción profesional, como la mediación, referida a cómo se puede transformar las estructuras cognitivo-emocionales del estudiantado y el carácter contextualizado de la práctica pedagógica; la formación, que involucra la actualización reflexiva sobre el saber pedagógico y disciplinar; la interacción, que constituye un aspecto fundamental en la relación de la persona docente con la sociedad, y facilita la configuración del conocimiento de su propia práctica (Dimaté, Tapiero, González, Rodríguez y Arcila, 2017). No obstante, respecto al desempeño, en el caso colombiano, no solo se puede hablar de procesos; sino que es necesario tomar en cuenta otros factores que lo determinan, como los contextos o escenarios y las partes involucradas. Al hacer referencia a contextos, se sabe que la labor docente del siglo XXI traspasa el límite de las aulas, por ello es necesario considerar cuatro escenarios: el aula, la institución educativa, el ámbito familiar y la comunidad (Dimaté et al., 2017).

En el caso de Indonesia, el desempeño del docente tiene cuatro competencias: pedagógica, personal, profesional y social, los cuales están establecidos como estándares nacionales de educación en su Reglamento de Gobierno (Andriani, Kesumawati y Kristiawan, 2018). López y López (2019), en su análisis de la tarea docente en México, llegan a la conclusión de que la persona docente debe ser mediadora cultural, pues fomenta la práctica de los saberes adquiridos dentro y fuera de la escuela, promueve que el estudiantado 
aprenda y practique comunitariamente a partir del análisis de su contexto, pues su misión no es construirle el futuro desde los contenidos, sino acercarle el presente desde la apertura al diálogo con y para las demás personas. De esa forma, contribuye con que el proyecto educativo logre la transformación de la escuela vinculada a la comunidad y a sus miembros.

Por su parte, Castro y Solís (2019) señalan que la evaluación del desempeño en México se precisa en el documento Perfiles, Parámetros e Indicadores para docentes y técnicos docentes, aprobado por el Instituto Nacional para la Evaluación de la Educación (INEE). En este, se considera como práctica docente al proceso por el cual la persona docente emplea sus habilidades, conocimientos y actitudes en el ejercicio de su profesión, con el fin de alcanzar sus objetivos. En Educación Primaria se configura en cinco dimensiones, como se observa en la Tabla 5

TABLA 5

Evaluación del desempeño de personas docentes y técnicas docentes. Ciclo escolar 2018-2019. Perfil, parámetros e indicadores para personas docentes y técnicas docentes

\begin{tabular}{|c|c|}
\hline Dimensión del perfil & Parámetros \\
\hline \multirow{3}{*}{$\begin{array}{l}1 \text { Docente que conoce a } \\
\text { su alumnado, sabe } \\
\text { cómo aprende y lo que } \\
\text { debe aprender }\end{array}$} & $\begin{array}{l}\text { Conoce los procesos de desarrollo y aprendizaje } \\
\text { infantiles }\end{array}$ \\
\hline & $\begin{array}{l}\text { Domina los propósitos educativos y los } \\
\text { contenidos escolares de la educación primaria }\end{array}$ \\
\hline & $\begin{array}{l}\text { Explica los referentes pedagógicos y los enfoques } \\
\text { didácticos del currículo vigente }\end{array}$ \\
\hline \multirow{4}{*}{$\begin{array}{l}2 \text { Docente que organiza } \\
\text { y evalúa el trabajo } \\
\text { educativo, y realiza una } \\
\text { intervención didáctica } \\
\text { pertinente }\end{array}$} & $\begin{array}{l}\text { Organiza su intervención docente para el aprendizaje } \\
\text { de sus estudiantes }\end{array}$ \\
\hline & $\begin{array}{l}\text { Desarrolla estrategias didácticas para que sus } \\
\text { estudiantes aprendan }\end{array}$ \\
\hline & $\begin{array}{l}\text { Utiliza la evaluación de los aprendizajes con fines de } \\
\text { mejora }\end{array}$ \\
\hline & Construye ambientes favorables para el aprendizaje \\
\hline \multirow{3}{*}{$\begin{array}{l}3 \text { Docente que se } \\
\text { reconoce como } \\
\text { profesional, que mejora } \\
\text { continuamente para } \\
\text { apoyar al alumnado en } \\
\text { su aprendizaje }\end{array}$} & $\begin{array}{l}\text { Reflexiona sistemáticamente sobre su práctica docente } \\
\text { como medio para mejorar }\end{array}$ \\
\hline & $\begin{array}{l}\text { Emplea estrategias de estudio y aprendizaje para su } \\
\text { desarrollo profesional }\end{array}$ \\
\hline & $\begin{array}{l}\text { Utiliza diferentes medios para enriquecer su desarrollo } \\
\text { profesional }\end{array}$ \\
\hline \multirow{4}{*}{$\begin{array}{l}4 \text { Docente que asume } \\
\text { las responsabilidades } \\
\text { legales y éticas } \\
\text { inherentes a su } \\
\text { profesión para el } \\
\text { bienestar del alumnado }\end{array}$} & $\begin{array}{l}\text { Considera los principios filosóficos, los fundamentos } \\
\text { legales y las finalidades de la educación pública } \\
\text { mexicana en el ejercicio de su función docente. }\end{array}$ \\
\hline & $\begin{array}{l}\text { Establece un ambiente favorable para la sana } \\
\text { convivencia y la inclusión educativa en su práctica } \\
\text { docente }\end{array}$ \\
\hline & $\begin{array}{l}\text { Considera la integridad y seguridad del alumnado en el } \\
\text { aula y en la escuela }\end{array}$ \\
\hline & $\begin{array}{l}\text { Demuestra altas expectativas sobre el aprendizaje de } \\
\text { todos sus estudiantes }\end{array}$ \\
\hline \multirow{3}{*}{$\begin{array}{l}5 \text { Docente que participa } \\
\text { en el funcionamiento } \\
\text { eficaz de la Escuela y } \\
\text { fomenta su vinculo con } \\
\text { la comunidad para } \\
\text { asegurar que todo el } \\
\text { alumnado concluya con } \\
\text { éxito su escolaridad }\end{array}$} & $\begin{array}{l}\text { Realiza acciones en la gestión escolar para contribuir a } \\
\text { la calidad de los resultados educativos }\end{array}$ \\
\hline & $\begin{array}{l}\text { Propicia la colaboración de los padres y madres de } \\
\text { familia y de distintas instituciones para apoyar la tarea } \\
\text { educativa de la escuela }\end{array}$ \\
\hline & $\begin{array}{l}\text { Considera las características culturales y lingüísticas de } \\
\text { la comunidad en el trabajo de la escuela }\end{array}$ \\
\hline
\end{tabular}

Fuente: Adaptado de Castro y Solís (2019).

Así pues, la propuesta de evaluación de desempeño docente en México considera los parámetros relacionados con la preparación y promoción de los aprendizajes, la profesionalidad docente, su relación con 
la comunidad y, además, incorpora la responsabilidad ética del ejercicio de la profesión que la diferencia de otros planteamientos.

Sepúlveda, Hernández, Peña, Troyano y Opazo (2019) mencionan cinco aspectos que componen el desempeño docente en Chile y que no difieren de otros países: habilidades intelectuales concretas; conocimiento de la asignatura; capacidades pedagógicas; identidad profesional y ética; capacidad para percibir y responder a las necesidades del estudiantado y el contexto. En relación con las competencias docentes, si bien la planificación de la enseñanza, la organización de contextos favorables para el aprendizaje, la metodología y evaluación, la autorreflexión sobre la práctica pedagógica, son consideradas como las más importantes, estas están determinadas por las condiciones y la organización escolar, especialmente por el liderazgo que ejerce el directivo de la IE (Casas, 2019). Hartinah et al. (2020) precisan que las habilidades pedagógicas se ven afectadas por muchas variables, como las habilidades mentales y físicas; los antecedentes familiares; la experiencia; las influencias organizacionales, como recompensas, liderazgo y los factores psicológicos que incluyen las motivaciones y actitudes.

De las propuestas mencionadas, se entiende que el desempeño docente, o práctica pedagógica, incluye todas las actividades que realizan como parte de su profesión: acciones de planificación de sus clases, acompañamiento permanente al desarrollo de las actividades de sus estudiantes, la puesta en práctica de un conjunto de estrategias durante las actividades en el aula, la evaluación del desempeño de sus estudiantes, la coordinación y trabajo colegiado entre pares y personas directivas de la institución, así como la participación permanente en acciones de formación y capacitación. A pesar de ello, no cabe duda de que el desempeño de las personas docentes siempre ha sido objeto de discusión, dado que los criterios para evaluarlas han ido cambiando con el tiempo.

\section{EL CASO PERUANO}

En el Perú surgió la necesidad de establecer parámetros claros y precisos respecto al desempeño docente, que permitieran una evaluación objetiva, como lo establece la Ley de la Carrera Pública Magisterial. Esta necesidad va de la mano con la urgencia de revalorización del trabajo docente, que se convirtió en una política nacional, expresada en el Proyecto Educativo Nacional a 2021, que se refiere en el objetivo estratégico 3 a la necesidad de asegurar la mejora profesional del personal docente, a partir la promoción de una carrera pública orientada hacia el desempeño responsable y efectivo, así como de una formación integral y permanente (Consejo Nacional de Educación, 2007). Esto significa que al estado y la sociedad les compete colaborar en el desarrollo y fortalecimiento profesional de la persona docente, al ofrecerle oportunidades de formación inicial y en servicio.

Así, el MINEDU elaboró el Marco del Buen Desempeño Docente con el propósito de mejorar la calidad educativa y en él se señala que la sociedad actual exige al profesorado una profesión transformada con capacidad investigativa, pensamiento crítico reflexivo, autonomía para la toma de decisiones que le permita optimizar sus estrategias de enseñanza; en suma, una nueva docencia (Ministerio de Educación [MINEDU], 2012).

Desde esa mirada globalizadora de la carrera docente, actualmente existen cuatro enfoques que demanda el desempeño del profesorado: enfoque sobre el aprendizaje, el cual implica cambiar la asimilación acrítica de los conocimientos para transformarlos en participación activa del estudiantado como constructor de su propio aprendizaje; enfoque sobre la persona aprendiz, en el cual se reconoce que el estudiantado es un ser único y valioso, autónomo para construir su propio aprendizaje, por lo cual debe ser valorado en su diversidad cultural; enfoque sobre las oportunidades de aprendizaje, no se puede dejar de entender que el aprendizaje traspasa las paredes de las aulas, por lo cual se deben considerar todos los espacios externos como válidos para el logro de competencias del estudiantado; finalmente, el enfoque sobre la pedagogía, que requiere una transformación de enseñanza básicamente oral, al uso de las diversas oportunidades de intercambio 
pedagógico continuo con el estudiantado (Ministerio de Educación [MINEDU], 2012). Sea cual sea el enfoque que se considere prioritario, la labor docente se concentra en el alumnado y la forma en cómo va a favorecer a que este desarrolle sus aprendizajes.

En nuestro país, el desempeño docente se encuadra en cuatro dominios que han sido explicitados en el Marco del buen desempeño docente. El primero está relacionado con las acciones que desarrolla la persona docente para preparar los aprendizajes de la población estudiantil; es decir, las tareas de planificación de las actividades pedagógicas, para lo cual se requiere que conozca y comprenda las particularidades de cada estudiante y su entorno, así como los contenidos del área que enseña, enfoques y procesos didácticos que le permita impulsar el desarrollo de capacidades. Al mismo tiempo, debe desarrollarlas de manera colegiada, asegurándose de que los aprendizajes que pretende lograr en el estudiantado, los procesos pedagógicos, los recursos que emplea y la evaluación que plantea, guarden coherencia entre sí, de manera que se evidencie en una programación curricular que sea permanentemente revisada. El segundo dominio se refiere a la enseñanza para el aprendizaje del estudiantado; el desarrollo de este requiere que la conducción de la enseñanza se desarrolle en un clima favorable para los aprendizajes y en un marco de sana convivencia democrática y respeto por la diversidad, esto con el uso de estrategias y recursos adecuados y dominio de contenidos disciplinares que permitan un aprendizaje reflexivo y crítico del estudiantado, en relación con sus intereses, experiencias y realidad; además de la aplicación de una evaluación permanente del aprendizaje que facilite la toma de decisiones y una retroalimentación de acuerdo con las necesidades particulares. El tercer dominio alude a la participación en la gestión de la escuela articulada a la comunidad. Involucra la actitud democrática, crítica y colaborativa con que el personal docente participa en la gestión institucional y colabora en la elaboración, revisión y mejora del Proyecto Educativo Institucional que favorece el desarrollo de aprendizajes de calidad; además de las relaciones de contribución, respeto y corresponsabilidad que pueda establecer con las familias, comunidad y otras instituciones y el Estado. El cuarto dominio se refiere al desarrollo de la identidad y el profesionalismo docente. Está referida al proceso y las experiencias de formación y desarrollo de la comunidad profesional de docentes. En este dominio, el cuerpo docente debe ser capaz de reflexionar sobre su práctica pedagógica y desarrollar procesos de aprendizaje permanente, tanto a nivel individual como colectivo, que le permitan construir y fortalecer su identidad profesional; además de ejercer su función en un marco de respeto por los derechos de las demás personas, mientras demuestra en todo momento valores como la justicia, la responsabilidad, la honestidad y el compromiso social (Ministerio de Educación [MINEDU], 2012).

\section{LA COMPETENCIA DIGITAL EN EL DESEMPEÑO DOCENTE}

Si bien el Marco del buen desempeño docente, sustentado en teorías de soporte metodológico y científico, establece de manera precisa y clara los dominios, capacidades e indicadores del desempeño docente en Perú, y como parte de uno de los desempeños señala que el docente debe usar creativa y pertinentemente las tecnologías de la información y comunicación que tiene a su alcance, no se ha avanzado mucho en la preparación y capacitación de docentes respecto a ello, lo cual ha quedado evidenciado en la forma en que se ha debido afrontar la coyuntura del aprendizaje remoto.

Por ello, el desempeño docente en el contexto actual, debe considerar necesariamente la incorporación de las nuevas tecnologías digitales. Ya la UNESCO (2008) precisaba que la integración de la tecnología en las aulas va a depender de la capacidad que las personas docentes tengan para abandonar la pedagogía tradicional y fusionar las TIC con las nuevas propuestas pedagógicas, de manera que les permita desarrollar sesiones de aprendizaje dinámicas que, a su vez, estimulen la interacción colaborativa y el aprendizaje cooperativo. Esto significa que, incorporar las tecnologías de la información y la comunicación al trabajo en las aulas requiere no solo de equipar a las instituciones educativas con estos recursos; sino que es necesario que todas las partes educativas sepan beneficiarse de las posibilidades didácticas que ofrecen, especialmente, a la labor del docente y al aprendizaje del estudiantado (Pozuelo, 2014). Ello requiere desarrollar competencias 
fundamentales, tanto en el uso innovador de las TIC como en la adquisición de fundamentos básicos sobre ellas, y profundizar el conocimiento y generarlo. Cabe destacar que, durante los procesos de enseñanzaaprendizaje, la incorporación de estos recursos se basa en las relaciones que se construyen entre el objeto de enseñanza (contenido), la actividad del personal docente (facilitador) y el proceso de aprendizaje del estudiantado (constructor); para lo cual los medios tecnológicos se constituyen en un valioso recurso que se emplea como un medio y no como fuente de conocimiento, con lo que caer en la pasividad de la escuela tradicional (Morales, 2013).

Durán, Gutiérrez y Prendes (2016) señalan que la competencia digital se tiene que concebir desde variados componentes, como el comunicativo, tecnológico, uso de la información y alfabetización digital. En el caso de la docencia, además se incorpora el aspecto pedagógico, referido a cómo se logra integrar las TIC de manera útil en el aula y evalúa las implicancias que tiene para la formación digital de los alumnos. Se deduce, entonces, que la competencia digital del docente no se circunscribe al conocimiento y uso de recursos digitales, sino que requiere de nuevos conocimientos, habilidades y actitudes que, sumados, van a desarrollar y fortalecer una práctica pedagógica innovadora que no limite el uso de las TIC solo para la búsqueda de contenidos, sino que permita el uso de aplicaciones y herramientas web para mejorar los aprendizajes del estudiantado (Suárez, Peláez y Flores, 2019). Su función primordial radica en ayudar al alumnado para que aprenda de manera autónoma, por lo que se promueve el desarrollo cognitivo y personal a través de actividades de aprendizaje que permitan el aprovechamiento de la extraordinaria información disponible en los medios tecnológicos y el uso pertinente de las TIC (Rangel, 2015).

El personal docente debe incorporar el uso de las tecnologías a su práctica pedagógica; sin embargo, esto debe hacerse de una manera reflexiva, que evalúe la pertinencia y utilidad en cada uno de los procesos o actividades que va a desarrollar. El uso reflexivo de las TIC es intencional y nace de la experiencia continua de su uso, bajo un proceso de análisis permanente que permita su incorporación efectiva en la enseñanza y aprendizaje. Dicho de otra forma, mientras mayor sea el nivel de incorporación reflexiva de la tecnología a la enseñanza, mucha mayor coherencia habrá entre los objetivos de aprendizaje, las estrategias, los contenidos, y el uso de las TIC (Valencia-Molina et al., 2016). Tejada y Pozos (2018) presentan tres habilidades docentes relacionadas con el uso de las tecnologías: las básicas, referidas a la alfabetización primaria que permita conocer y comprender las TIC al identificar sus potencialidades didácticas; las habilidades de profundización, que permiten su aplicación en la práctica docente, con un mayor manejo, como resultado de la experimentación y práctica intensiva, lo que le permitirá al personal docente mayores posibilidades de aplicación didáctica; finalmente, las habilidades referidas a la generación de conocimiento, consideradas como el nivel más alto de desarrollo de la competencia tecnológica, que pretende ya no usar los recursos, sino crear conocimiento a través de ellos para fomentar la creatividad y la innovación.

Esta exigencia de incorporar la tecnología se ve reforzada en el PEN a 2036, en el que se afirma que es necesario aprovechar las variadas y crecientes oportunidades que ofrecen los avances tecnológicos para efectivizar el aprendizaje continuo, pues las TIC, en formatos y medios accesibles, posibilitan variadas oportunidades para el desarrollo de experiencias de aprendizaje significativas y para brindar recursos educativos novedosos y pertinentes (Consejo Nacional de Educación, 2020); dado que las tecnologías de la información y la comunicación representan una nueva forma de vida para la ciudadanía del siglo XXI, en la cual podrán sobrevivir y crecer aquellas personas que desarrollen competencias para consumir, producir y divulgar información de forma eficaz, eficiente y rápida a través de diversos entornos y herramientas digitales (Area y Guarro, 2012). Esto significa que el profesorado del siglo XXI necesita una adecuada formación en el manejo de la tecnología, a fin de que pueda emplearla efectivamente en las aulas. Esta no debe ser solo como parte de su preparación profesional inicial, sino que también debe mantenerse durante los procesos de formación continua, para así asegurar una actualización permanente, como lo exige el mundo actual.

No es suficiente establecer con precisión los dominios, capacidades e indicadores del desempeño docente si no se tiene la posibilidad de verificarse en la práctica. De ahí surge la exigencia de evaluar el desempeño 
del personal docente, a pesar de que este siempre ha sido un tema sumamente controversial, puesto que ha enfrentado a los dos sectores involucrados: Estado y profesorado.

En muchos países del mundo no está generalizada esta práctica, básicamente por la carencia de instrumentos adecuados, como lo ha expresado la propia comunidad docente. En Perú, el Proyecto Educativo Nacional plantea la necesidad de evaluar al cuerpo docente para su acceso y permanencia en la carrera, a través de un programa nacional de evaluación con la aplicación de mecanismos técnicos, transparentes y equitativos (Consejo Nacional de Educación, 2007), para lo cual se elaboraron, posteriormente, instrumentos que permiten recoger esa información en función de las dimensiones y desempeños que establece el MBDD.

Respecto a la evaluación de desempeño, Martínez y Guevara (2015) lo precisan como un proceso sistemático, que busca valorar la calidad del desenvolvimiento de las personas docentes en el proceso de aprendizaje del estudiantado mediante un monitoreo constante. Esto significa que no está referida a la verificación de conocimientos, sino que está orientada a valorar de qué manera son capaces de cumplir responsablemente sus tareas pedagógicas en el aula y cómo promueven en sus estudiantes la práctica de estrategias efectivas de aprendizaje. Así pues, la evaluación del desempeño permite analizar y valorar la práctica pedagógica en un contexto determinado y bajo criterios específicos que facilitan determinar sus fortalezas y los aspectos por mejorar con la implementación de diversas estrategias que fomentan el desarrollo profesional.

\section{Metodología}

La presente investigación es fruto de una profunda y sistemática investigación documental que ha considerado, fundamentalmente, la revisión de fuentes primarias, como libros, artículos de revistas científicas indexadas, documentación oficial de instituciones públicas, documentos de investigación de instituciones nacionales e internacionales y normas técnicas relacionadas con el propósito de identificar y precisar los criterios que caracterizan al desempeño docente desde una perspectiva holística, acorde a la época en que se desarrolla la educación.

Las palabras clave fueron: competencias del docente, evaluación docente, práctica pedagógica. Se utilizaron las bases de datos Scopus, Web of Science, Scielo y Redalyc; con un periodo de búsqueda de publicación de los artículos no mayor a diez años de antigüedad.

Aplica como protocolo la Declaración Prisma para la elegibilidad de los artículos, de acuerdo a la secuencia que se plantea en la Figura 1. 


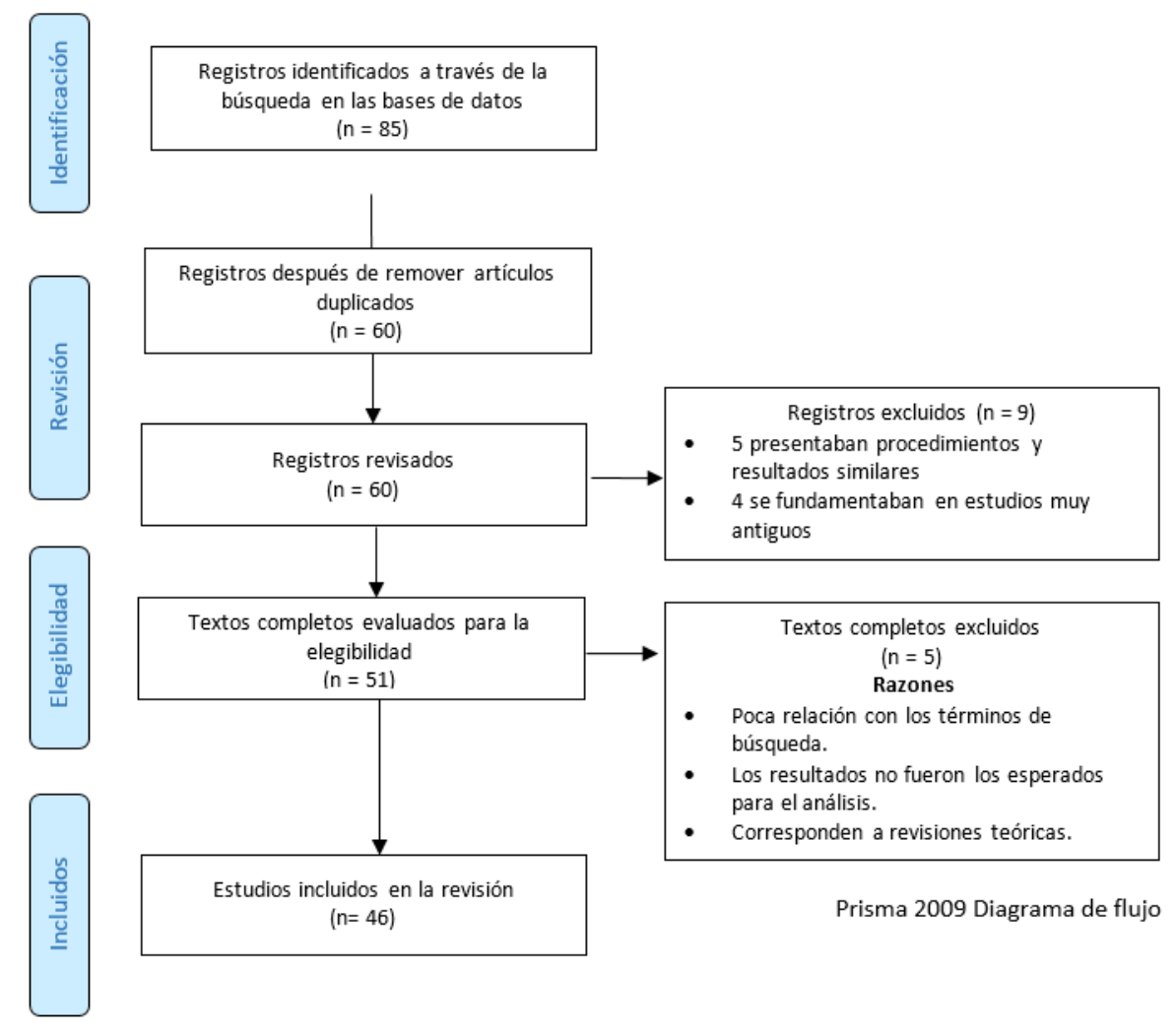

FIGURA 1

Diagrama de flujo para determinar la elegibilidad de los artículos científicos Fuente: sitio web de PRISMA

El proceso de elegibilidad de los artículos se inició con la búsqueda y selección de 85 fuentes alojadas en las bases de datos mencionadas. Luego, se contrastaron los artículos y se descartaron aquellos que contenían información muy semejante; lo cual permitió que se revisaran minuciosamente 60 artículos, de los cuales se excluyeron 9 por fundamentarse en estudios demasiado antiguos. Se procedió a una nueva revisión de las 51 fuentes y se encontró que 5 de ellas, no contenían resultados que sirvieran para el propósito de la investigación. En consecuencia, se incluyen 44 estudios como sustento para este estudio.

\section{Resultados}

Como resultado del análisis de los documentos de referencia e investigaciones enfocadas en el desempeño docente, se puede señalar lo siguiente:

En todos los países del mundo se han desarrollado políticas educativas orientadas a favorecer el mejoramiento de la práctica pedagógica, por lo cual se han emitido variadas normativas que han sentado las bases acerca de la labor docente y la importancia que tiene dotar al profesorado de competencias que le permita un óptimo desenvolvimiento en las aulas. Los modelos y enfoques pedagógicos determinan las estrategias y recursos que la persona docente debe emplear en las aulas para desarrollar los aprendizajes del estudiantado; en consecuencia, se relacionan con el tipo de práctica pedagógica que desarrollan.

En países como Indonesia, México, Colombia y Chile existen criterios establecidos sobre el desempeño docente, los cuales se han venido usando para evaluarlo. Entre ellos, existen similitudes relacionadas con aspectos referidos al desempeño en el aula: metodologías, evaluación, planificación; pero también, en cada caso particular se precisa la necesidad de considerar otros factores externos, como el contexto institucional y social en el que, sin duda, el profesorado, también desempeña funciones, e incluso, los factores personales. 
En el caso peruano se han logrado establecer criterios referidos al desempeño docente, los cuales están enmarcados en una política de evaluación permanente; que se orienta a tres dimensiones específicas en las que se desenvuelve el personal docente: pedagógica, política y cultural, las cuales se extraen de las nueve competencias que se precisan en el MBDD (Ministerio de Educación [MINEDU], 2012); sin embargo, al evaluarlas, hasta la actualidad, solo se han considerado criterios referidos al desempeño en el aula, los cuales se valoran a través de las rúbricas establecidas para ello (RM 138-2018). Estas evalúan 5 desempeños:

1. Involucra activamente al estudiantado en el proceso de aprendizaje.

2. Promueve el razonamiento, la creatividad o el pensamiento crítico.

3. Evalúa el progreso de los aprendizajes para retroalimentar al estudiantado y adecuar su enseñanza.

4. Propicia un ambiente de respeto y proximidad.

5. Regula positivamente el comportamiento del estudiantado.

Por otra parte, como se puede comprobar, en ninguno de los indicadores se considera, de manera clara y precisa, el uso pedagógico de las tecnologías.

\section{ConcLuSiONES}

Con base en el análisis, se propone un perfil docente que señale las competencias que le permitan desempeñarse eficientemente. La persona docente del siglo XXI debe observar los aspectos sociales, políticos y económicos de su contexto, para analizar y adecuar su práctica profesional; debe ser líder, gestionar y mediar los aprendizajes de sus estudiantes; conocer de las teorías y los modelos curriculares; planificar los procesos educativos, y sobretodo, comunicarse asertivamente y trabajar en equipo. Asimismo, debe investigar, emprender e innovar permanentemente, también saber usar las tecnologías de la información y comunicarse de manera apropiada; presentar una elevada capacidad de resiliencia y facilidad de adaptación a los cambios para aprender de lo nuevo y priorizar su aplicación; tener empatía y tolerancia, y centrar su pedagogía en el ser humano, la felicidad y el bienestar social.

La competencia digital, como parte del desempeño docente, es prioritaria, dado que las tecnologías de la información y la comunicación ya forman parte de la vida cotidiana, por lo que la persona docente debe usarlas, no solo como recursos, sino como medios para promover aprendizajes significativos y autónomos. No obstante, esto requiere de una formación y capacitación permanente para su uso responsable y adecuado, así como de un proceso de reflexión y evaluación de su pertinencia y utilidad según el propósito que se desea alcanzar.

\section{RECOMENDACIONES}

El Ministerio de Educación peruano debe elaborar instrumentos de evaluación del desempeño docente, que incluyan las cuatro dimensiones y nueve competencias que se precisan en el marco del buen desempeño y que involucran los procesos de preparación y enseñanza para el aprendizaje del estudiantado, la participación en la escuela y comunidad, y el desarrollo profesional y personal (Ministerio de Educación [MINEDU], 2012). Ello posibilitará que comprenda que su tarea no se circunscribe al ámbito de las aulas y a las metodologías de enseñanza, sino que, como señala Girón (2014), además del compromiso con sus estudiantes, tiene una gran responsabilidad con su institución y con su entorno social.

Con respecto a las acciones relacionadas con el proceso de planificación de los aprendizajes, los criterios fundamentales a considerar como parámetros de desempeño docente son: la selección y contextualización de competencias, capacidades y conocimientos según la realidad del estudiantado, así como de las estrategias y recursos pertinentes para alcanzar los propósitos educativos, pues, como señalan Dimaté et al. (2017), es necesario que la persona docente, al ser mediadoras del aprendizaje, contextualice su práctica pedagógica. 
En cuanto a la enseñanza para los aprendizajes, se deben priorizar los criterios relacionados con el uso de estrategias que promuevan la autonomía, el pensamiento crítico, reflexivo, creativo y complejo, para lo cual, según Padilla (2016), cada profesional de la educación debe reflexionar y evaluar su propio desempeño. Por otra parte, se debe considerar el uso pertinente de los recursos y la incorporación de las TIC como elemento fundamental en el presente siglo.

La participación en la gestión del currículo y la escuela implica que la persona docente no se puede abstraer de la realidad sobre la cual debe tomar acción. En ese sentido, debe considerarse su participación en decisiones ligadas al currículo y políticas escolares a través de criterios como el que señala Montenegro (2007), quien se refiere al modelo colombiano de evaluación del desempeño docente, como es la participación en el desarrollo coherente del PEI, y lo que precisa Robalino (2005) sobre la participación en la organización, implementación y evaluación de políticas educativas de todo nivel.

Respecto a su vínculo con la comunidad, se hace prioritario que el profesorado establezca una relación de comunicación fluida con las familias y que oriente su labor en pro de la mejora de la comunidad, con lo que atenderá la problemática social y ambiental que afecta al mundo. En ese sentido los criterios que deben incluirse como parte del desempeño docente son los aportes al desarrollo de la cultura, la sociedad y la actuación responsable con el entorno (Montenegro, 2007; Girón, 2014).

Dadas las nuevas necesidades educativas, se debe priorizar la formación y capacitación docente en tres habilidades fundamentales relacionadas con la competencia digital, como destacan Tejada y Pozos (2018): conocimiento y comprensión de las TIC; uso pertinente, reflexivo y didáctico de estas; y generación de conocimiento que fomente la creatividad y la innovación. Dichos criterios, que forman parte del desempeño del profesorado del siglo XXI, deberán ir acompañados del soporte tecnológico que debe proveer el Estado a docentes y estudiantes, al facilitar su acceso a la tecnología y equipar las instituciones educativas con recursos. Sin embargo, lo más importante es que todas las partes del sistema educativo, como señala Pozuelo (2014), sepan y puedan beneficiarse de las posibilidades didácticas que ofrecen las TIC.

\section{ReFERENCIAS BIBLIOGRÁFICAS}

Andriani, S., Kesumawati, N. y Kristiawan, M. (2018). The influence of the transformational leadership and work motivation on teachers performance. International Journal of Scientific and Technology Research, 7(7), 19-29. Recuperado de https://bit.ly/3ia9xR0

Area, M. y Guarro, A. (2012). La alfabetización informacional y digital: Fundamentos pedagógicos para la enseñanza y el aprendizaje competente. Revista Española de Documentación Cientifica, 35(MONOGRAFICO), 46-74. doi: https://doi.org/10.3989/redc.2012.mono.977

Ausubel, D. (1978). Psicología Educativa. Un punto de vista cognoscitivo. México: Trillas.

Bravo, G., Loor, M. y Saldarriaga, P. (2016). La teoría constructivista de Jean Piaget y su significación para la pedagogía contemporánea. Dominio de Las Ciencias, 2, 127-137. Recuperado de https://dialnet.unirioja.es/servlet/artic ulo? codigo $=5802932$

Cárdenas, J. (2015). Rúbrica y desempeño docente en la provincia de Huancayo. (Tesis doctoral). Universidad Nacional del Centro del Perú. Perú. Recuperado de https://bit.ly/3dZDmFn

Casas, A. (2019). Liderazgo pedagógico, nuevas perspectivas para el desempeño docente. Investigación Valdizana, 13(1). doi: https://doi.org/10.33554/riv.13.1.171

Castro, D. y Solís, R. (2019). Breve análisis de algunos aspectos normativos y técnicos de la evaluación del desempeño docente para la permanencia del Servicio Profesional Docente. Tendencias Pedagógicas, 34, 153-168. doi: http s://doi.org/10.15366/tp2019.34.012

Cóndor, B. H. y Remache, M. (2019). La evaluación al desempeño directivo y docente como una oportunidad para mejorar la calidad educativa. Cátedra, 2(1), 116-131. doi: https://doi.org/10.29166/catedra.v2i1.1436 
Consejo Nacional de Educación. (2007). Proyecto Educativo Nacional al 2021. Recuperado de http://www.minedu. gob.pe/DeInteres/xtras/PEN-2021.pdf

Consejo Nacional de Educación. (2020). Proyecto Educativo Nacional al 2036. Recuperado de http://www.cne.gob.p e/uploads/publicaciones/2020/proyecto-educativo-nacional-al-2036.pdf

De Zubiría, J. (1999). Los modelos pedagógicos: Hacia una pedagogía dialogante. Bogotá: Fundación Alberto Merani.

Dimaté, C., Tapiero, O., González, C., Rodríguez, R. y Arcila, M. (2017). La evaluación del desempeño docente. FOLIOS, 46, 83-95. Recuperado de http://www.redalyc.org/articulo.oa?id=345951474007\%0ACómo

Durán, M., Gutiérrez, I. y Prendes, M. (2016). Análisis conceptual de modelos de competencia digital del profesorado universitario. 15(1), 97-114. doi: https://doi.org/10.17398/1695-288X.15.1.97

Eleizalde, M., Parra, N., Palomino, C., Reyna, A. y Trujillo, I. (2010). Aprendizaje por descubrimiento y su eficacia en la enseñanza de la Biotecnología Learning by discovery and its effectiveness in teaching the Biotechnology. Revista de Investigación, 71(34), 271-290. Recuperado de http://www.redalyc.org/articulo.oa?id=376140386013

Girón, R. (2014). Acompañamiento pedagógico del supervisor educativo en el desempeño docente. (Tesis de Licenciatura). Recuperado de http://biblio3.url.edu.gt/Tesario/2014/05/08/Giron-Rocio.pdf

González, V. (2014). Innovar en docencia universitaria: algunos enfoques pedagógicos. InterSedes: Revista de Las Sedes Regionales, 15(31), 51-68. Recuperado de http://www.redalyc.org/articulo.oa?id=66631887005\%0A

Granda, S. (2002). La evaluación del desempeño docente: análisis de sus resultados. Universitas: Revista de Ciencias Sociales y Humanas, 2, 5-18. doi: https://doi.org/10.17163/uni.n2.\%x

Hartinah, S., Suharso, P., Umam, R., Syazali, M., Lestari, B. D., Roslina, R. y Jermsittiparsert, K. (2020). Teacher's performance management: The role of principal's leadership, work environment and motivation in Tegal City, Indonesia. Management Science Letters, 10(1), 235-246. doi: https://doi.org/10.5267/j.msl.2019.7.038

Ley 29944 - Ley de Reforma Magisterial. Diario Oficial El Peruano. Lima, Perú, 25 de noviembre de 2012. Recuperado de http://www.leydereformamagisterial.com/

López, V. y López, M. G. (2019). Evaluación al desempeño docente: concepto , sentido e implicaciones en la instrumentalización.Rleei, 3(1),21-32. Recuperado de http://cresur.edu.mx/OJS/index.php/RLEEI_CRESU $\mathrm{R} /$ article/view/323/241

Martinez, G. y Guevara, A. (2015). La evaluación del desempeño docente. Ra Ximhai, 11(4), 113-124. Recuperado de http://www.redalyc.org/articulo.oa?id=46142596007\%0ACómo

Ministerio de Educación [MINEDU]. (2012). Marco del Buen Desempeño Docente. Recuperado de http://www.min edu.gob.pe/pdf/ed/marco-de-buen-desempeno-docente.pdf

Ministerio de Educación [MINEDU]. (2016). Currículo Nacional de la Educación Básica. Ministerio de Educación. Recuperado de http://www.minedu.gob.pe/curriculo/pdf/curriculo-nacional-de-la-educacion-basica.pdf

Ministerio de Educación [MINEDU]. (2019). Evaluación Ordinaria del Desempeño Docente 2017 Nivel Inicial-Tramo I. Informe nacional Recuperado de http://evaluaciondocente.perueduca.pe/media/11565198575Informe-Fina 1-EDD-2017-Tramo-I.pdf

Montenegro, I. (2007). Evaluación del desempeño docente Fundamentos, modelos e instrumentos. Bogotá, Colombia: Editorial Magisterio. Recuperado de http://bibliotecadigital.magisterio.co/libro/evaluaci-n-del-desempe-o-doc ente-fundamentos-modelos-e-instrumentos

Morales, V. (2013). Desarrollo de competencias digitales docentes en la educación básica. Apertura, 5(1), 88-97. Recuperado de http://www.redalyc.org/articulo.oa?id=68830443008

Naciones Unidas. (2015). Declaración universal de los derechos humanos. Naciones Unidas. Recuperado de https://w ww.un.org/es/documents/udhr/UDHR_booklet_SP_web.pdf

Naciones Unidas - CEPAL. (2018). Agenda 2030 y los Objetivos de Desarrollo Sostenible Una oportunidad para América Latina y el Caribe. Naciones Unidas. Recuperado de https://repositorio.cepal.org/bitstream/handle/11362/4 0155/24/S1801141_es.pdf

Ordóñez, J. (2002). Pedagogía crítica y educación superior. Revista Educación, 26(2), 185-196. Recuperado de http: //www.redalyc.org/articulo.oa?id=44026218\%0ACómo 
Ortiz, A. (2017). Modelos Pedagógicos y Teorias del Aprendizaje ¿Cómo elaborar el modelo pedagógico de la institución educativa?. Recuperado de https://bit.ly/3i67E7V

Padilla, M. (2016). Desempeño Docente y la Investigación Acción. Horizonte de La Ciencia, 1(1), 51-53. Recuperado de http://revistas.uncp.edu.pe/index.php/horizontedelaciencia/article/view/131/139

Piaget, J. (1969). Psicología y pedagogía. Barcelona, España: Ariel.

Pozuelo, J. (2014). ¿Y si enseñamos de otra manera? Competencias digitales para el cambio metodológico. Caracciolos, 2(1). Recuperado de https://bit.ly/32W9aV2

Rangel, A. (2015). Competencias docentes digitales: propuesta de un perfil. Pixel-Bit. Revista de Medios y Educación, 46, 235-248. Recuperado de https://www.redalyc.org/articulo.oa?id=36832959015

R.M. No 138-2018-MINEDU. Modifica el instrumento "Rúbricas de observación de aula". Diario Oficial El Peruano. Lima, Perú, 27 de marzo de 2018. Recuperado de http://evaluaciondocente.perueduca.pe/media/1152452423 6RM-138-2018-MINEDU-Modifica-Rubrica-Observacion-Aula.pdf

Robalino, M. (2005). ¿ Actor o Protagonista\#? PRELAC, 1, 6-23. https://unesdoc.unesco.org/ark:/48223/pf0000 144666

Robalino, M. (2007). Los docentes pueden hacer la diferencia: apuntes acerca del desarrollo profesional y el protagonismo docente. La Professionnalisation Des Enseignants de l'education de Base\#: Les Recrutements sans Formation Initiale. Recuperado de https://bit.ly/2GaqRIu

Roegiers, X. (2016). Marco conceptual para la evaluación de competencias. Cuestiones Fundamentales y Actuales Del Curriculo y El Aprendizaje, 4. Recuperado de http://www.ibe.unesco.org/sites/default/files/resources/ipr4-roe giers-competenciesassessment_spa.pdf

Sepúlveda, A., Hernández, C., Peña, S., Troyano, M. y Opazo, M. (2019). Evaluation of teacher performance in Chile: Perception of poorly evaluated teachers. Cadernos de Pesquisa, 49(172), 144-163. doi: https://doi.org/10.159 $0 / 198053145792$

Suárez, S., Peláez, A. y Flórez, J. (2019). Las competencias digitales docentes y su importancia en ambientes virtuales de aprendizaje. Reflexiones y Saberes, 10,33-41. Recuperado de https://revistavirtual.ucn.edu.co/index.php/R evistaRyS/article/view/1069/1510

Tejada, J. y Pozos, K. (2018). Nuevos Escenarios y Competencias Digitales Docentes: Hacia la Profesionalización Docente con TIC. Profesorado, Revista de Curriculum y Formación Del Profesorado, 22(1), 25-51. Recuperado de https://recyt.fecyt.es/index.php/profesorado/article/view/63620

UNESCO. (2002). Proyecto Regional de Educación para América Latina y El Caribe. Recuperado de http://www.tar ea.org.pe/images/PRELAC_Educ.pdf

UNESCO. (2008). Estándares de Competencia En TIC Para Docentes. En Organización de las naciones unidas para la educación la ciencia y la cultura (Unesco). UNESCO. Recuperado de http://www.eduteka.org/EstandaresD ocentesUnesco.php

UNESCO. (2014). ENSEÑANZA Y APRENDIZAJE\#: lograr la calidad para todos. Organización de las Naciones Unidas para la Educación, la Ciencia y la Cultura. Recuperado de https://unesdoc.unesco.org/ark:/48223/pf0 000226159

Valencia-Molina, T., Serna-Collazos, A., Ochoa-Angrino, S., Caicedo-Tamayo, A. M., Montes-González, J. A. y Chávez-Vescance, J. D. (2016). Competencias y estándares TIC desde la dimensión pedagógica: Una perspectiva desde los niveles de apropiación de las TIC en la práctica educativa docente. Pontificia Universidad Javeriana. Recuperado de http://www.unesco.org/new/fileadmin/MULTIMEDIA/FIELD/Santiago/pdf/Competencia s-estandares-TIC.pdf

\section{INFORMACIÓN ADICIONAL}


Lucía Angélica Esquerre Ramos, et AL. Retos del deSempeño docente en el siglo XXI: Una VISIÓN DEL ...

Cómo citar:: Esquerre Ramos, L.A. y Pérez Azahuanche, M.A. (2021). Retos del desempeño docente en el siglo XXI: una visión del caso peruano. Revista Educación, 45(2). Recuperado de http://doi.org/10.15517 /revedu.v45i1.43846 